\title{
Türkiye'nin kuzeyinde çocuk hastaların diş tedavilerinde genel anestezi ne sıklıkta tercih ediliyor?
}

\author{
How often is general anesthesia preferred in dental treatment \\ of child patients in the north of Turkey?
}

\author{
Aysun Çağlar Torun \\ Ondokuz Mayıs Üniversitesi Diş hekimliği Fakültesi, Ağız Diş ve Çene Cerrahisi Anabilim Dalı, Samsun, Turkey
}

\section{Özet}

Amaç: Genel anestezi ile diş tedavisi, hekime ve hastaya konforlu bir süreç sağlamakta kısa sürede birçok tedavi hastaya uygulanabilmektedir. Bu çalışma ile Ondokuz Mayıs Üniversitesi Diş Hekimliği Fakültesi'nde genel anestezi altında yapılan diş tedavilerinin retrospektif olarak incelenmesi amaçlanmıştır.

Gereç ve Yöntem: Ocak 2015-Eylül 2015 tarihleri arasında genel anestezi altında yapılan diş tedavileri, retrospektif olarak değerlendirilmiştir. Hastaların yaş, kilo, genel anestezi endikasyon nedenleri, yapılan diş tedavileri ve ek sistemik hastalıkları değerlendirildi.

Bulgular: Hastalar ortalama yaş grubu $8 \pm 6$, ortalama ağırlıkları ise $25 \pm 17$ kg olarak belirlendi. Hastaların \%53.8'i erkek \%46.2'si kız hastalardı. Diş tedavisi uygulanan hastaların \%59.9'unu ( $n=790)$ sağlıkI ancak kooperasyon kurulamayan hastalar, \%32.8'i $(n=431)$ geniş cerrahi operasyon geçirecek hastalar, \%7.3'ünü ( $n=97)$ zihinsel/fiziksel engeli olan hastalardan oluşmaktaydı. Hastaların \%11.6'sına $(n=153)$ restoratif diş tedavisi, \%59.8'ine $(n=788)$ diş çekimi, $\% 20.5^{\prime}$ ine $(n=270)$ restoratif diş tedavisi + diş çekimi, \%7.3'üne ( $n=97$ ) çene cerrahisi, \% 0.8'ine periodontal tedavi uygulanmıştır.

Sonuç: Davranış yönetim stratejileri ile çocuk hastaların ikna edilerek diş tedavileri uygulanabilir. Ancak son yıllarda bu uygulamadan giderek uzaklaşılmakta, farmakolojik yöntemler ön plana çıkmaktadır. Genel anestezinin kullanımı diş hekimliği uygulamalarında hızla artmaktadır. Ancak gereksiz genel anestezi uygulamalarından kaçınmak için endikasyonu belirlemede kullanılan yöntemlerin etkin ve doğru bir şekilde uygulanması gerekmektedir. Çalışmamızda genel anestezi sağlıklı çocuk hastalarda yüksek oranda tercih edilmiştir. Türkiye'de diş hekimlerinin genel anestezi endikasyonunu belirlemede kullandıkları yöntemlerin ve bunların doğru şekilde uygulanıp uygulanmadığının incelendiği ileri çalışmalara ihtiyaç vardır.

Anahtar Sözcükler: Çocuk; diş hekimliği; genel anestezi.

\begin{abstract}
Introduction: With general anesthesia, dental treatment provides a comfortable process to the patient and the physician. In short time, many treatments can be applied to the patients. This study aimed to retrospectively examine the dental treatments performed under general anesthesia at Ondokuz Mayıs University Faculty of Dentistry.

Methods: Dental treatments under general anesthesia between January 2015 and September 2015 were evaluated retrospectively. Age, weight, reasons for general anesthesia indication, dental treatment and additional systemic diseases were evaluated.

Results: Patients were determined as mean age group $8 \pm 6$, mean weight $25 \pm 17 \mathrm{~kg} .53 .8 \%$ of the patients were male and $46.2 \%$ of the patients were female. $59.9 \%(n=790)$ of the dental treatment patients were healthy, but not cooperatable, 32.8\% $(n=431)$ had extensive surgery and $7.3 \%(n=97)$ were mentally/physically disabled patients. Restorative dental treatment was performed in $11.6 \%$ of the patients $(n=153)$, tooth extraction in $59.8 \%(n=788)$, restorative dental treatment + tooth extraction in $20.5 \%(n=270)$, jaw surgery in $7.3 \%(n=97)$ and $0.8 \%$ periodontal treatment.

Discussion and Conclusion: Behavior management strategies can be used to convince child patients and to treat teeth. However, in recent years, this practice has gradually moved away from the practice and pharmacological methods have come to the forefront. The use of general anesthesia is increasing rapidly in dental practice. However, in order to avoid unnecessary general anesthesia applications, the methods used to determine the indications need to be applied effectively and correctly. In our study, general anesthesia was highly preferred in healthy children. There is a need for further studies in Turkey to examine the methods used by dentists to determine the indication for general anesthesia and whether they are applied correctly.

Keywords: Child; dentistry; general anesthesia.
\end{abstract}


$\mathrm{D}$ ş hekimliği uygulamalarında birçok işlem esnasında sedasyon ve genel anestezinin kullanımı giderek artmaktadır. $^{[1,2]}$ Genel anestezi ile diş tedavisi, hekim ve hasta/hasta yakınına konforlu bir süreç sağlamakta kısa sürede birçok tedavi hastaya uygulanabilmektedir. Yüksek anksiyete düzeyi, düşük kooperasyon, geniş restoratif ve/veya cerrahi işlem ihtiyacı olan hastalar ile tıbbi açıdan yüksek risk taşıyan hastalarda, sıklıkla genel anestezi/sedasyon tercih edilmektedir. ${ }^{[3,4]}$ Zihinsel/ fiziksel engeli olan hastaların yanı sıra yüksek anksiyete nedeniyle kooperasyon kurulamayan sağlıklı çocuk hastalarda da genel anestezi uygulamaları giderek artmaktadır. ${ }^{[5]}$ Sağlıklı çocuk hastaların genel anestezi altında diş tedavileri yapıldıktan sonra rutin diş bakımına ve tedavilerine geri dönmeleri gerekmektedir. Ancak çocukların ve yakınlarının diş bakımı ile ilgili önerilere uymadıkları birçoğunun tekrar diş tedavisine ihtiyaç duydukları belirlenmiştir. ${ }^{[4,6,7]}$ Bu nedenle bu hasta grubunda tekrarlayan genel anestezi uygulamalarına ihtiyaç olabilmektedir. Ancak genel anestezi altında diş tedavisi, gelişmiş hastane koşulları, bu konuda uzman ekip gerektirmesi ve muhtemel solunumsal ve kardiovasküler yan etkileri nedeniyle endikasyonlarının doğru belirlenmesi gereken bir yöntemdir.

Amerikan Pediatrik Diş Hekimliği Akademisi (AAPD) ve Avrupa Pediatrik Diş Hekimliği Akademisi (EAPD) hazırladıkları kılavuzlarda genel anestezi altında diş tedavisinin endikasyonlarını ve kontrendikasyonlarını belirtmişlerdir. ${ }^{[8]}$ Davranışsal yönetim problemleri, dental korku ve anksiyete, mental retardasyon, geniş ve komplike dental tedavi ihtiyacı genel anestezi endikasyonlarından bazılarıdır. Diş hekimleri, hastaların psikolojik ve medikal durumları ile uygulanacak tedaviyi değerlendirdikten sonra non-farmakolojik yöntemler ile hasta ve doktor arasında iletişimi sağlamalı ve tedavileri uygulamalıdırlar. Non-farmakolojik yöntemlerin başarısızlığı durumunda ise genel anestezi kararı verilebilir.

Bu çalışma ile Ondokuz Mayıs üniversitesi Diş Hekimliği Fakültesinde yapılan genel anestezi uygulamalarının retrospektif olarak incelenmesi ve hasta profillerinin değerlendirilmesi amaçlanmıştır.

\section{Gereç ve Yöntem}

Bu çalışma ile Samsun Ondokuz Mayıs Üniversiesi Diş hekimliği Fakültesinde, Ocak 2015-Eylül 2015 tarihleri arsında genel anestezi altında yapılan tüm diş tedavileri, retrospektif olarak değerlendirilmiştir. Verilerin toplanmasında diş hekimliği fakültesi veri tabanı kullanılmıştır. Ancak elektronik ortamda meydana gelen arıza nedeniyle veriler kısıtlıdır. Hataların yaş, cinsiyet, kilo, sistemik hastalıkları, yapılan diş tedavileri ve genel anestezi endikasyon nedenleri değerlendirilmiştir.

Bütün hastaların istatiksel değerlendirmelerinde SPSS 20,0 paket programı kullanıldı. İstatiksel analiz verileri ortalama \pm standart sapma ve $\mathrm{n}(\%)$ olarak sunuldu.

\section{Bulgular}

Hastalar ortalama yaş grubu $8 \pm 6$, ortalama ağırlıkları ise $25 \pm 17$ kg olarak belirlendi. Hastaların \%53.8'i erkek \%46.2'si kız hastalardı. Diş tedavisi uygulanan hastaların \%59.9'unu ( $\mathrm{n}=790)$ sağlıklı ancak kooperasyon kurulamayan hastalar, \% 32.8'i $(n=431)$ geniş tedavi ihtiyacı olan hastalar, \%7.3'ünü ( $n=97)$ zihinsel/fiziksel engeli olan hastalardan oluşmaktaydı (Tablo 1). Hastaların \%11.6'sına ( $n=153)$ restoratif diş tedavisi, \%59.8'ine $(\mathrm{n}=788)$ diş çekimi, \%20.5'ine $(\mathrm{n}=270)$ restoratif diş tedavisi + diş çekimi, \%7.3'üne ( $n=97)$ çene cerrahisi, \%0.8'ine $(n=10)$ periodontal tedavi uygulanmıştır. Hastaların \% 73'ünün $(n=963)$ sistemik bir hastalığı bulunmazken, \%27'sinde $(n=355)$ vardı (Tablo 2).

Hastalarda varolan sistemik hastalıklarının \%7.5'ini $(n=100)$ mental retardasyon, \%4.3'ünü $(n=56)$ astım bronşiole, \%3.9'unu ( $n=51)$ serebral palsi, \%3.1'ini $(n=41)$ epilepsi, \%3'ünü ( $n=38)$ mental retardasyon + epilepsi, \%2.3'ünü $(n=30)$ kongenital kalp hastalığı \%2.9'unu $(n=39)$ ise diğer hastalıklar (kromozom anomalileri, metabolik hastalıklar gibi) oluşturmaktaydı (Tablo 3).

Kliniğimizde aynı anda birçok bölüm ameliyata dahil olarak hastaların diş tedavilerini tamamlanmaktadır. Bu nedenle verilerde bölümlerden değil yapılan tedavilerden bahsedilmektedir.

\section{Tablo 1. Hastaların genel anestezi endikasyonları}

\begin{tabular}{lcc} 
Endikasyon & Sayı & $\%$ \\
\hline Sağlıklı/kooperasyon eksikliği & 790 & 59.9 \\
Zihinsel/fiziksel engel & 97 & 7.3 \\
Geniş cerrahi işlem & 431 & 32.8 \\
\hline
\end{tabular}

Tablo 2. Operasyon türüne göre hastaların dağılımı

\begin{tabular}{lcc} 
Operasyon türü & Sayı & $\%$ \\
\hline Restoratif diş tedavisi & 153 & 11.6 \\
Diş çekimi & 788 & 59.8 \\
Restoratif diş tedavisi+diş çekimi & 270 & 20.5 \\
Periodontal tedavi & 10 & 0.8 \\
Çene cerrahisi & 97 & 7.3 \\
\hline
\end{tabular}

Tablo 3. Sistemik hastalık varlığına göre hastaların dağılımı

\begin{tabular}{lcc} 
Sistemik hastalık & Sayı & $\%$ \\
\hline Sistemik hastalık yok & 963 & 73 \\
Sistemik hastalık var & 355 & 27 \\
Astım bronşiole & 56 & 4.3 \\
Kongenital kalı hastalığı & 30 & 2.3 \\
Serebral palsi & 51 & 3.9 \\
Epilepsi & 41 & 3.1 \\
Mental retarde+epilepsi & 38 & 3 \\
Mental retarde & 100 & 7.5 \\
Diğer & 39 & 2.9 \\
\hline
\end{tabular}




\section{Tartışma}

Bu çalışma ile diş hekimliği uygulamalarında genel anestezinin sağlıklı ancak kooperasyon kurulamayan çocuklarda yaygın olarak kullanıldığı tespit edilmiştir. Pediatrik diş hekimliğinde hasta ve hekim arasında iletişim problemleri ile karşılaşılabilir. Bu problemlerin çözümü için diş hekiminin iletişim, empati koçluk, tolerans, esneklik ve aktif dinleme konularında bilgili olması gerekmektedir. ${ }^{[9,10]}$ Davranış yönetim teknikleri kullanılarak hastalar ikna edilebilir, diş tedavileri uygulanabilir. ${ }^{[11,12]}$ Ancak son yıllarda bu uygulamadan giderek uzaklaşılmakta, farmakolojik yöntemler ön plana çıkmaktadır. ${ }^{[13]}$ Yapılan birçok çalışma ile genel anestezi uygulamalarının diş hekimliğinde hızla arttığı, bunun nedeninin davranış yönetim tekniklerinin uygulanmasında başarısızlık olduğu bildirilmektedir. ${ }^{[14,15]}$ Genel anestezi invaziv bir yöntem olması, hayatı tehdit edici birçok komplikasyona neden olabilmesi nedeniyle lüzum halinde tercih edilmesi gereken bir yöntemdir. Bu nedenle diş hekimliği uygulamalarında da non-farmakolojik yöntemler başarı ile denenmeli, ikna edilemeyen çocuk hastalar genel anesteziye yönlendirilmelidir. Bu çalışmada genel anestezi uygulanan hastaların büyük bir kısmı (\%59.9) kooperasyon kurulamayan sağlıklı çocuk hastalardan oluşmaktaydı. Bunun nedeninin çocuk hastaları ikna etmede kullanılan davranış yönetim tekniklerinin klinikler tarafından etkin bir şekilde kullanılmaması ile ilgili olabileceği düşünüldü. Ancak veri eksikliği nedeniyle bu konu değerlendirilemedi.

Zihinsel/fiziksel engelli hastalar genel anestezinin tercih edildiği diğer bir hasta grubudur. Bu hastalarda anatomik deformiteler ve kooperasyon eksikliği nedeniyle diş tedavilerinin yapılması mümkün değildir. Bu nedenle genel anestezi bu hastalarda tercih edilmektedir. Ayrıca geniş cerrahi işlem uygulanacak lokal anestezi ile yeterli anestezinin sağlanamayacağı hastalarda da genel anestezi tercih edilmektedir. Genel anestezini muhtemel komplikasyonları ek hastalık varlığında artmaktadır. ${ }^{[16]}$ Bu nedenle problemli hastalar genel anesteziye yönlendirilirken ayrıntılı muayene ve planlama yapılmalıdır. Ameliyat sonrası postoperatif bakım veya yoğun bakım ihtiyacı olabilecek hastalar önceden belirlenmeli gerekli tedbirler alınmalıdır. Uygun koşulların olmadığı merkezlerde hastalara genel anestezi uygulanmamalıdır.

Bu çalışmanın bazı limitasyonları mevcuttur. Operasyon öncesi değerlendirme esnasında genel anestezi endikasyonunu belirlemede kliniklerin hangi yöntemleri kullandığı ile ilgili veriler eksiktir. Bu nedenle sağlıklı çocuk hasta sayısının yüksek olmasının nedenleri değerlendirilememiştir. Eldeki verilerin kısıtlı olmasına rağmen, yüksek hasta sayısı ve sağlıklı hastalardaki yüksek genel anestezi sayısına sahip olması nedeniyle bu çalışmanın, bu konuya araştırmacıların dikkatini çekebileceği ve ileri araştırmalara ışık tutabileceği düşünüldü.

\section{Sonuç}

Genel anestezi, sağlıklı çocuk hastaların tedavilerinin uygulanabilmesi için diş hekimlerinin çok tercih ettiği bir yöntem ha- line gelmiştir. Türkiye'de diş hekimlerinin genel anestezi endikasyonunu belirlemede kullandıkları yöntemlerin ve bunların doğru şekilde uygulanıp uygulanmadığının incelendiği ileri çalışmalara ihtiyaç vardır.

Çıkar çatışması: Bildirilmemiştir.

\section{Kaynaklar}

1. El Batawi HY, Panigrahi P, Awad MA. Perceived outcomes and satisfaction of Saudi parents and their children following dental rehabilitation under general anesthesia: A 2-year follow-up. J Int Soc Prev Community Dent 2014;4:S153-60.

2. Lehtonen V, Sándor GK, Ylikontiola LP, Koskinen S, Pesonen P, Harila $V$, Anttonen V. Dental treatment need and dental general anesthetics among preschool-age children with cleft lip and palate in northern Finland. Eur J Oral Sci 2015;123:254-9.

3. Savanheimo N, Vehkalahti MM. Five-year follow-up of children receiving comprehensive dental care under general anesthesia. BMC Oral Health 2014;14:154.

4. Mallineni SK, Yiu CK. Dental treatment under general anesthesia for special-needs patients: analysis of the literature. J Investig Clin Dent 2016;7:325-31.

5. Aminabadi NA, Najafpour E, Aghaee S, Sighari Deljavan A, Jamali Z, Shirazi S. Use of general anaesthesia in paediatric dentistry: barriers to discriminate between true and false cases. Eur Arch Paediatr Dent 2016;17:89-95.

6. Mitchell L, Murray JJ. Management of the handicapped and the anxious child: a retrospective study of dental treatment carried out under general anaesthesia. J Paediatr Dent 1985;1:9-14.

7. Berkowitz RJ, Moss M, Billings RJ, Weinstein P. Clinical outcomes for nursing caries treated using general anesthesia. ASDC J Dent Child 1997;64:210-1, 228.

8. American Academy of Pediatric Dentistry. Guideline on the elective use o minimal, moderate, and deep sedation and general anesthesia in pediatric dental patients. Pediatr Dent 2004;26:95103.

9. Hosey MT; UK National Clinical Guidelines in Pediatric Dentistry. UK National Clinical Guidelines in Paediatric Dentistry. Managing anxious children: the use of conscious sedation in paediatric dentistry. Int J Paediatr Dent 2002;12:359-72.

10. Rosenberg M; American Dental Association. New guidelines for the use and teaching of general anesthesia and sedation by dentists. J Mass Dent Soc 2010;58:22-7.

11. Landier W, Tse AM. Use of complementary and alternative medical interventions for the management of procedure-related pain, anxiety, and distress in pediatric oncology: an integrative review. J Pediatr Nurs 2010;25:566-79.

12. Adair SM, Rockman RA, Schafer TE, Waller JL. Survey of behavior management teaching in pediatric dentistry advanced education programs. Pediatr Dent 2004;26:151-8.

13. Wilson S. Pharmacological management of the pediatric dental patient. Pediatr Dent 2004;26:131-6.

14. Hicks CG, Jones JE, Saxen MA, Maupome G, Sanders BJ, Walker $L A$, et al. Demand in pediatric dentistry for sedation and general 
anesthesia by dentist anesthesiologists: a survey of directors of dentist anesthesiologist and pediatric dentistry residencies. Anesth Prog 2012;59:3-11.

15. Bimstein E, Azari AF, Riley JL 3rd. Predoctoral and postdoctoral students' perspectives about pediatric dental behavior guidance.
J Dent Educ 2011;75:616-25.

16. Ashley PF, Williams CE, Moles DR, Parry J. Sedation versus general anaesthesia for provision of dental treatment to patients younger than 18 years. Cochrane Database Syst Rev 2015:CD006334. 